https://doi.org/10.48009/2_iis_2008_351-360

\title{
A MODELING TECHNIQUE FOR BPR BASED ON EXTENDED PETRI NET
}

\author{
Tang Zhi-wei, University of Electronic Science and Technology of China, tangzw@uestc.edu.cn \\ Zong Dai, Alfred University, dai@alfred.edu
}

\begin{abstract}
This article develops an extended Petri net model based on EEPC, for the purpose of achieving the correctness and validity of qualitative and quantitative business process analysis, as warranted by the literature. The proposed model then is applied to a business license application process at a government agency and the findings are reported.
\end{abstract}

Keywords: Business process reengineering (BPR), Extended event process chain (EEPC), Petri net and Reachability

\section{INTRODUCTION}

Business Process Reengineering (BPR) is one of the most influential approaches to transforming an enterprise since 1980s [4]. BPR is a thought of reformation as well as a systematical process of implementation [20]. In the BPR implementation, the description and analyses of the current business processes are an essential step, through which the enterprise can have a thorough understanding of the current circumstances, and discover the existing problems, then it may correctly identify the sticking point of the enterprise which may provide a new way for optimizing and reengineering the process [15].

The literature documents various researches on modeling business process reengineering. For example, Petri network [19, 25, 16], Date Flow Diagram (DFD) [7], Automation Workflow (AW) [18], the simulation method for reproducing the dynamic behaviors [1], I * model [6], Extended Event-Process Chain (EEPC) [11], Unified Modeling Language [5], IDEF series [13].
However, almost all of them are proposed from different perspectives and for the different objectives, but not entirely based on and for the business process. Therefore, for the purpose of achieving the correctness and validity of qualitative and quantitative process analysis, it is warranted that a BPR modeling approach be developed, which can describe the logical structure of the business process while making quantitative analysis of dynamic factors such as time.

After analyzing two prevalent process modeling technologies-EEPC and Petri net, this article proposes an Extended Petri net model based on EEPC, then applies the model to the clinic processes in a government agency and reports the findings.

\section{EXTENDED PETRI NET BASED ON EEPC}

As a modeling language, Petri graphically depicts the structure of a distributed system as a directed bipartite graph with annotations. As such, a Petri net has place nodes, transition nodes, and directed arcs connecting places with transitions [19, 22, 23, 24].

Through showing logic relations, such as serial, parallel, choosing and circular between the enterprise activities, Petri net has offered the advantage for measuring and diagnosis of the process.

Four similar structures “And-split” “And-join” “Or-split” and “Or-join” often appear in Petri net, and it is very difficult to distinguish them quickly and clearly. In order to express route structure better, we add special symbols in the structure (See Fig.1).

Figure 1: Extended route expression

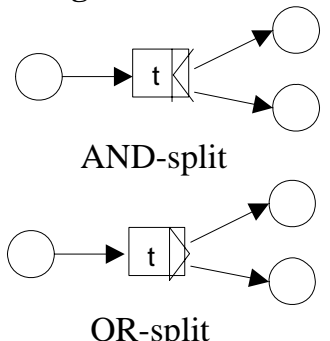

OR-split

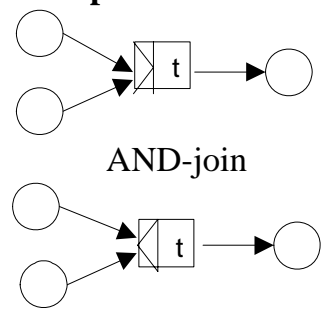

OR-join

After adding triangles at the input and output of

transition, the structure of “OR" and “AND” can be 
distinguished more clearly. The principle is that if the triangle formed by arrows is the same as direction of the triangle of the transition, it means "AND", otherwise "OR".

As a modeling technology based on state, Petri net is intuitive and visual, and has rigorous modeling semantic and mathematic analyzing abilities, and therefore has certain advantages in modeling the process. However, it should be noted that Petri net only discusses the construction of controlling and shifting, and describes the dynamic characters of the business process, but does not involve the data and the change of data. Furthermore, traditional Petri pays no attention to an influential factor in process appraisal-time. These are unfavorable for a comprehensive and quantitative analysis of the process performance. Petri net is only used to analyze the validity of the process, to guarantee the process going fluently without any dead lock, but fails to analyze the performance and optimization of the process.

Extended event process chain (EEPC) is a quantitative analytical method based on time. It considers time and station, and validates the simulative ability of the model by building some two-dimensional judging quadrants. It remedies the deficiency of Petri in terms of objective and quantitative. However, EEPC only judges the time and the utilization of station, and sets up general branch, without reflecting the logic characteristic of the process. Thus it is not suitable to describe the process macroscopically and collectivity.

Based on Petri net and EEPC, we propose a new model: the Extend Petri net based on EEPC, by merging the pros and cans of them and incorporating the functional units or organizational units.
The main design principles are: first, three factors-waiting time, emergence time are added to reflect functional units for calculating the station utilization, delay time of each station and cycle time.

Then, simulate and re-engineer the process based on these factors. This extended technology not only reflects the logic construct of the process, but also can calculate and judge the time and other factors quantitatively, and ascertain the exactness and validity of analyzing the process qualitatively and quantitatively.

The proceeding steps are as follows.

Step 1: Describe the process according to the sequence of the event (See Fig. 2). The main factors includes place, transition, directional arc, processing time, delay time, interval time, moving time, functional units and so on. If the process is complex, it can be exploded into a lower level in line with the guidelines of "Layer-by-Layer" and "Top to down".

Step 2: Analyze the validity of the process. It needs to analyze the inherent behavior and structure of the process, judge process's correctness and validity [7]. It also means to ascertain exactness and reachability of the process from the perspectives of structure and logic, without any unusual structural problems, such as a dead lock (the incident being blocked and unable to continue), or a live lock (the incident operating among them constantly as a dead circulation), or a dead transition.

The reachability graph or reachability tree of Petri net will be used to ascertain the validity of process's structure [9].

Figure 2 (a): The graphic description of process
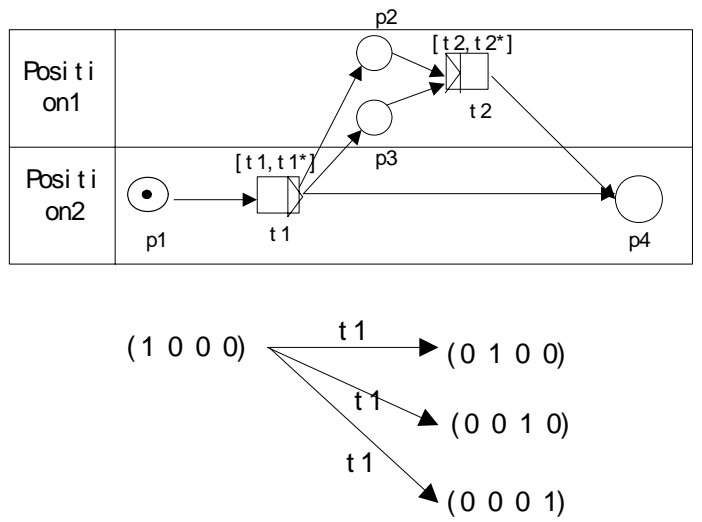
The Fig. 2 (b) shows transition t2 can't be executed forever, which means this process has dead transition.

Figure 3 (a): The graphic description of process

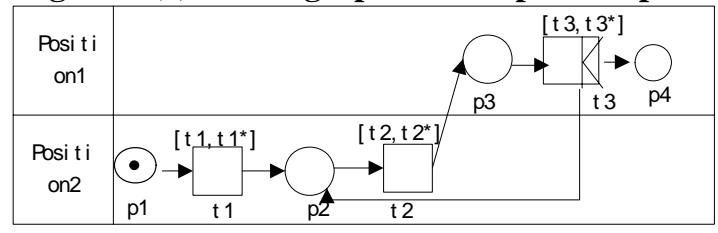

Figure 3 (b): The reachability graph of Fig. 3 (a)

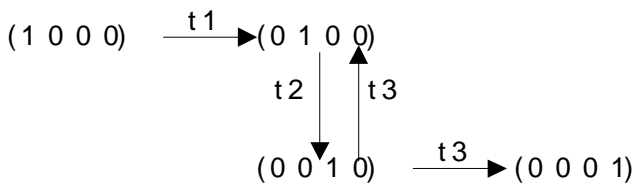

The Fig. 3 (b) shows each case will circulate in t2 and $\mathrm{t} 3$ because this process has live dead and will circulate ceaselessly. Meanwhile, a good course must have a clear beginning and ending. There should not be any task to carry out at the ending. But in this process, t2 and t3 will still be implemented at the very ending, so this process violates the requirements.

Step3: Estimating the performance of the process. At this stage, some performance and indexes of the process will be calculated, and then redesigned so as to improve the original process. Depending on the idea of EEPC, new model will calculate the stations' utilization, cycle time and wait time of the process, form a two-dimensional quadrant, and propose corresponding solutions.

Utilization of station indicates how much work is performed in relation to its work capacity, which depends on the number of servers and working time. When process redesigning takes place, stations with too low utilization rate should have more work, or over-loaded stations should transfer some of their excess work to others. Delay time at a station is the average sum of the moving time and the waiting time for service. When redesigning business processes, the delay time for each station should be reduced as much as possible. Cycle time is the total amount of time customers spend in the entire business process, consisting of moving time, waiting time, and processing time at all stations through which customers pass. Based on station's utilization and customer's delay time, a two-dimensional quadrant is formed and the process can be classified into four situations [12] (See Fig. 4).

Figure 4: Performance-based situations

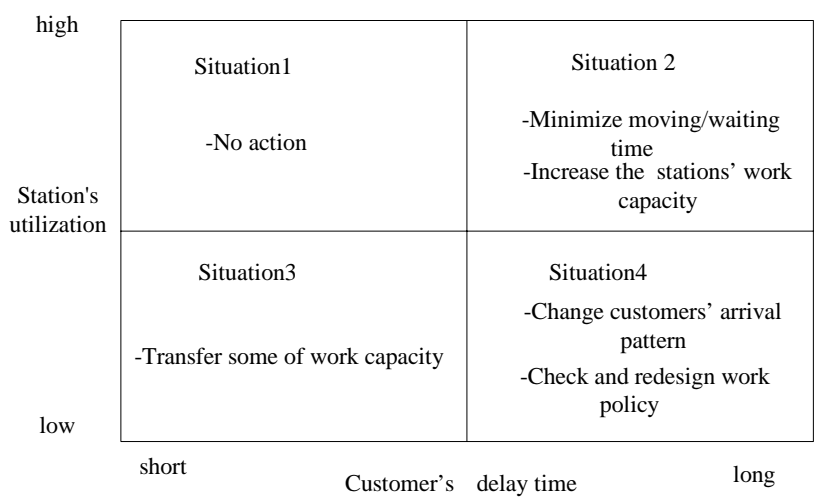

\section{APPLICATION OF EEPC-BASED EXTEND PETRI NET}

\subsection{Current situation Analysis}

An interview is conducted with the director of Chengdu bureau of business administration in China. It is found that the process of applying for a business license is the same as the most of governmental 
operation's process, especially administrative examination and certificate issuing. Each office, such as the director of bureau office, construction and personal safety department, community development department, construction examination department, and account department, play an important role during this process. So an applier often succeeds in getting the license after unnecessary running upstairs and downstairs among these five offices. Moreover, each office processes data independently and there is no integrated data processing system. So an applier must spend lots of time in applying for a business license.

Here is the present process of applying for a business license, figure 5 . In this chart, it works when the applier arrives, one by one each 10 minutes. At the beginning, an applier comes to director of bureau office and fills a requisition table, 3 to 5 minutes lost. After that, he/she will go up 2 floors to the construction and personal safety office, and make sure to get the trade place and residence permit, 5 to 8 minutes for going upstairs and 6 to 8 minutes for inquiring. If the trade place is legal, he/she still goes down 2 floors back to the community development department. If not, he/she has to leave. In the community development department, the applier is considered to wonder how to use the trademark, and he/she has to apply for a trademark if needed. In fact, $60 \%$ of the appliers need to do so. Of course, he/she will pay a sum of money to the account department. After solving the trademark problem, he/she will be waiting for the approval on the commercial zoning site.

Finally, the applier will show these charts and licenses to the director and then gain the signature of the director. Doing this may cost about 20 minutes, because the director is usually very busy. Even if all done, he/she also goes to pay the check to the account department and bring back the receipts to the director of the bureau office and get the business license. Obviously it takes time to finish every step during the whole process because each office locates at different place. To solve this problem, it is really necessary to restructure the application process.

Figure 5: The model of current activities flow

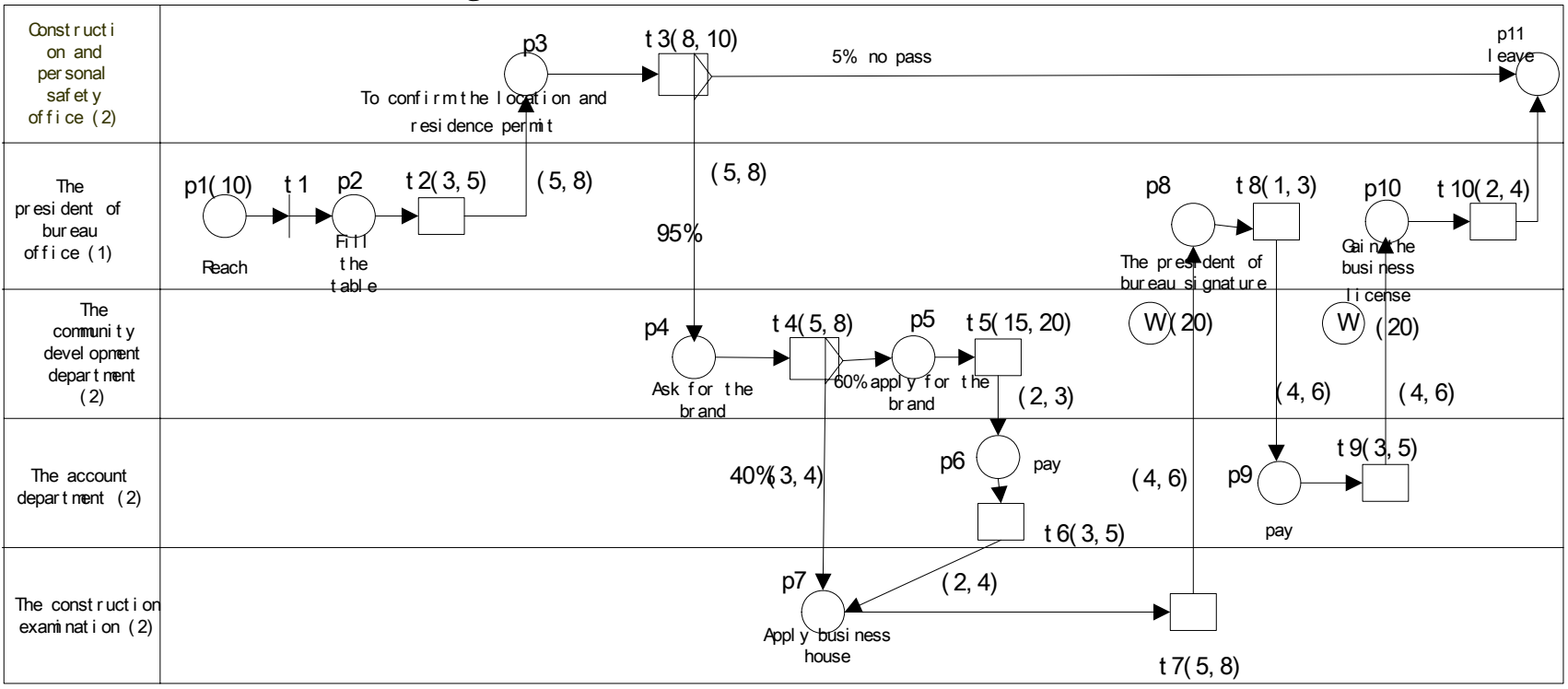

\subsection{The correctness analysis of business license flow}

After using the fundamental element Petri network based on the expansion of EEPC to describe the current situation of the flow (figure 6), the reachability graph using the new model is needed to apply on the structural and logical accurate analysis to the flow. The existing business license application flow can be explained by figure 6, through analyzing, it accords completely with the three requirements of the accuracy definition of the flow, each state can achieve the final goal, and moreover, the dead lock, live lock and dead transition don't occur in the process. Thus, it can be confirmed that the structure of the license acquirement flow is structurally and logically correct and effective. 


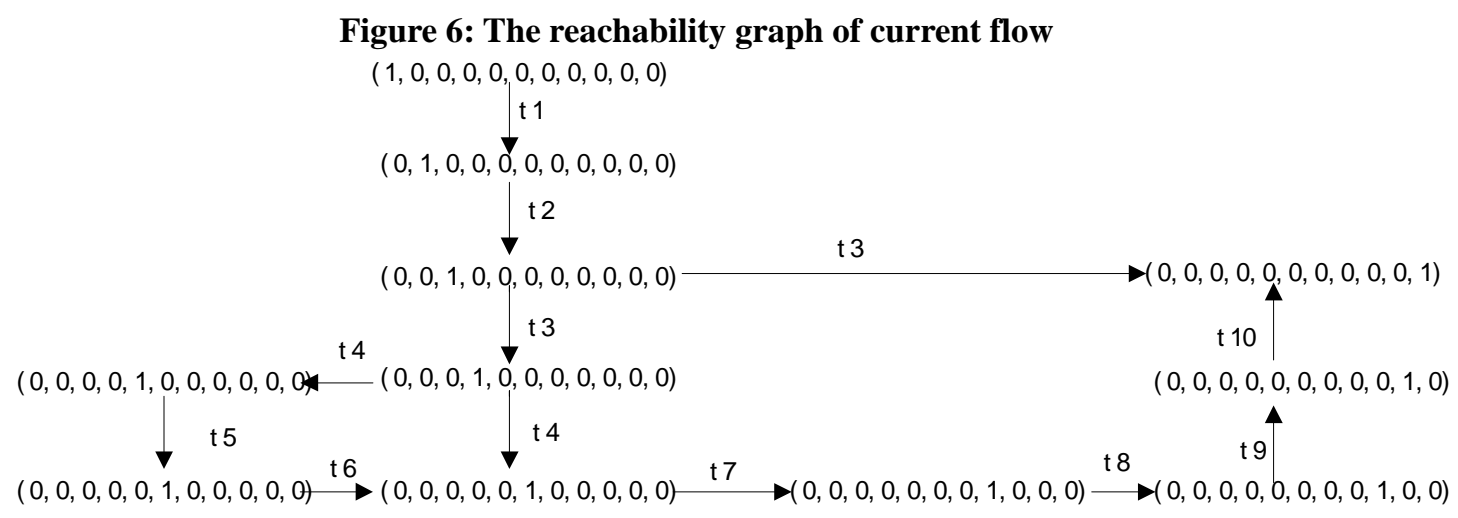

\subsection{The analysis of simulation and performance of business license application process}

In addition to the correctness analysis of the structure and logic of the flow, and the time factor being introduced in the Petri network model based on the expansion of EEPC, the time simulation and performance analysis are needed in the course of simulation. The time that different applicants in the application process cost isn't completely the same. It is not a precise value, but only a rough time range, thus, in the process of simulation, the stochastic function should be adopted to acquire the stochastic time, which occurred at each stage; and furthermore, the stochastic time should be regarded as sample. For instance, 3 to 5 minutes is taken to determine business location, then, by adopting the stochastic function, the numerical value between 3 and 5 is taken in each simulation as sample value, this value generally take two decimal.

Pointing to every single department involved in the application of business license, by adopting the random function, three indexes respectively, namely, site utilization ratio, delay time and general period can be gained. Utilization ratio is the ratio of actual amount of work of each department to its work ability; a department's work competence depends mainly on the time for handling an instance and the quantity of the staff in the department.

Departments with an excessive high or low utilization ratio all need to be re-organized. The department with excessively high utilization ratio should increase more staff or reduce their workloads, and the department with excessively low utilization ration should increase their workloads or transfer some of their responsibilities to other sites. Delay time is the waiting time in each department and the time they move form one site to another (counting from the starting point).

It is the direct factor that influences the public's degree of satisfaction, so it is better to minimize the delay time in the process of reorganization. In the process of the simulating with related software, the obtained value is the average of all the sample values in this process. The general period includes the time of working, moving and waiting, which is the total time public take in the process of applying business license, and also the main target of reorganization.

In order to increase public's satisfaction, the general period should be minimized. At the same time, for the simulation system adopts random function, in order to testify the validity of the sample value, it is necessary to calculate the standard deviation. For example, if we take 1000 samples for the simulating process of applying for business license, and the standard deviation of period is 2.4 , then it means the random value is able to satisfy the validity of samples.

In addition, it shall be noticed that when counting the time, the possibility of implement needs to be considered. The ultimate time value should be service time multiplied by the choice degree of implement (percentage); with regard to the parallel route, it is better to adopt that consuming in the longest one.

In the process of simulating the various factors in applying for the business license, supposing the sample is 1000, the total period will be 116.01 minutes, and the period standard deviation will be 2.4 . The time consuming in every site, the site utilization ration and delay time of each department are as table 1 show: 
Table 1: The date analysis of each site in the current flow

\begin{tabular}{|c|c|c|c|}
\hline Evaluation factor & $\begin{array}{c}\text { Affairs } \\
\text { consuming time }\end{array}$ & Delay time & $\begin{array}{c}\text { Site } \\
\text { utilization ratio }\end{array}$ \\
\hline $\begin{array}{c}\text { The president of bureau } \\
\text { office }\end{array}$ & 9.20 & 51.43 & $89.24 \%$ \\
\hline $\begin{array}{c}\text { The Construction and } \\
\text { personal safety office }\end{array}$ & 9.00 & 5.01 & $45.02 \%$ \\
\hline $\begin{array}{c}\text { The community } \\
\text { development department }\end{array}$ & 16.00 & 3.51 & $84.95 \%$ \\
\hline $\begin{array}{c}\text { The account department } \\
\text { The construction } \\
\text { examination department }\end{array}$ & 6.10 & 7.94 & $31.79 \%$ \\
\hline
\end{tabular}

\subsection{Strategy analysis of the reorganization of the flow in applying for business license}

First, the whole process of business license application is full of two-way communication between the public and service departments. For example, in the beginning of the flow, the applicant applies, and gets the application form from the director of the bureau, then provides information on the business location to construction and personal safety office and the information will be finally confirmed in the construction and personal safety office. Therefore the reorganization should stress department's efficiency and the cooperation between these departments thus enhancing the efficiency of the whole process.

Secondly, the process of transacting business license involves a series of routes, such as sequence, selection, and concurrence. It strides over different functional departments, and follows the order of activities, which has reflected the general rule of the flow of government affairs. By sequential route, the person first receives and fills in the table, then get the business location, brand and building examined and verified, finally receive the license again from the director of bureau office. By the route of choosing, if the applicant is approved when affirming the business location, then he can go on to make other information affirmed, otherwise he may leave; after the brand information has been checked in the community development department, one may apply for a brand, pay, or directly enter the construction examination department for examination and approval.

Thirdly, the flow of transacting business license is a series of activities which begins with applications from the public, enterprises or social communities and ends with providing business license to them with the aim to satisfy and serve its applicants. It focuses on public's interests rather than itself. Therefore, when judging the performance of it, they are more considerate to the rapid response to public's demands, the period efficiency of transaction rather than their own costs and profits. For example, when examining the business sites, staff of the construction and personal safety office always considerate the effects that business activities play on the city and the public. Aiming to satisfy the public and enhance the efficiency of government is also the important goal of the reorganizing activities flows in the government affairs.

\subsection{The reorganization of the flow for transacting business license}

On the basis of the time public delay at each department and the utilization ratio of every site, combined with strategies on reorganization, a two-dimension quadrant can be established to categorize them so as to raise corresponding guide for reorganization. The categorization of the five departments involved in business license flow can be seen as the following table. 
Figure 7: Performance-based situations of business license flow

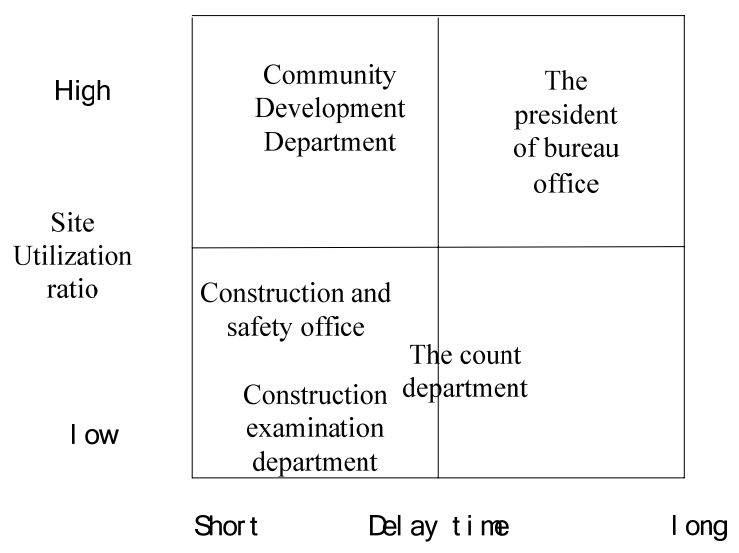

From the figure, it can be seen that the utilization ratio for community development department is high and public could only delay here within a short period. Considering from both the public and the department, it is relatively ideal and does not need any reorganization.

The director of bureau office is a station with a high utilization ratio and a longer delay period. Through analyzing relevant data it can be found that the reason public delay here is because of their long waiting time. Therefore, measures to switch the staff's burdens to other departments or increase more staff here may be of help. Actually, the fact to add a new director is impossible, so it is better to reduce his burdens and transfer a part of his jobs to other departments.

Through analysis the job of sending sheets and tables may be transferred to another department Meanwhile, under the present working conditions, documents need to be signed by the director are all of paper form, however, if the director can browse the content in digital data through computer, the process for examination and approval will be more efficient, thus the delay phenomenon will be relieved. In addition, the found of a unified digital data provides a new means for the director which facilitates the browsing of data by various means, thus he could get a more thorough understanding of the development of different jobs.

Public do not take too much time in construction and personal safety office and construction examination department, so it is possible to reduce the staff or increase their burdens in order to enhance their utilization ratio. Considering that the director' burden need to be relieved, it is better to transfer the director's job of sending sheets and tables to them. Moreover, it can be found that these two stations are responsible for information inquiring which do not require too much competence of the staff, and they have their own computers, so if they could efficiently use the network to transfer information and establish an integrated information system, instead of the current independent data processing, then there will be more efficient information sharing.

Finally, the integrated information system could unify the format of data and information, thus reducing the burden of the staff for information inquiring. In view of this situation, it may be considered to integrate the two departments into construction and examination offices. It is noticeable that this involves the adjustment of the personnel. However, it may create resistance. Therefore, the adjustment would need the support from the superior administrator and the whole staff.

Compared with other departments, situations of the account department are relatively specific for it requires high quality to the financial staff. Moreover, the account department is involved in various affairs of other departments. Especially there will be more report forms of statistics at the end of every month and year. Therefore, the utilization ratio of this department is unstable. This department can be reconstructed by enhancing its data processing and by establishing a canonical digital data so as to enhance its efficiency. Meanwhile, it can be found that public always shuttle between the financial department and president office for several times, so we may consider placing these two departments in close proximity to each other.

According to the above discussion, the main tasks in the reconstructing process are as follows: integrate construction examination department and construction and personal safety office into 
construction and examination department; transfer the job of sending sheets and tables to construction and examination department, so that public could receive them from construction and examination department at the time they entering the office block and inquire corresponding information; according to the sequence of the flow, put closely related departments nearly, e.g. put construction and examination department and community development department nearly in the first ground, and put the financial office and president office nearly in the second floor.

In addition, in the traditional transacting flow, the same information are always stored, processed and managed in different departments. The great development of information technology brings a new chance for effective information management in the public service. Therefore, in the process of reconstructing the flow for transacting business license, we shall also make full use of the information technology it order to share information in the flow and facilitate the inquiring and handling of information, thus greatly enhance the efficiency of these departments so that the business license could be transacted rapidly.

According to the above guide for reorganization of the flow in transacting business license, we made a resembling model (the sample size is 1000, and the data used is a mean). After comparing the evaluating data of achievements of this model with that of the current situation, we can get the results as in the following figure 8 and table 2 .

Figure 8: The analysis model of after reorganization

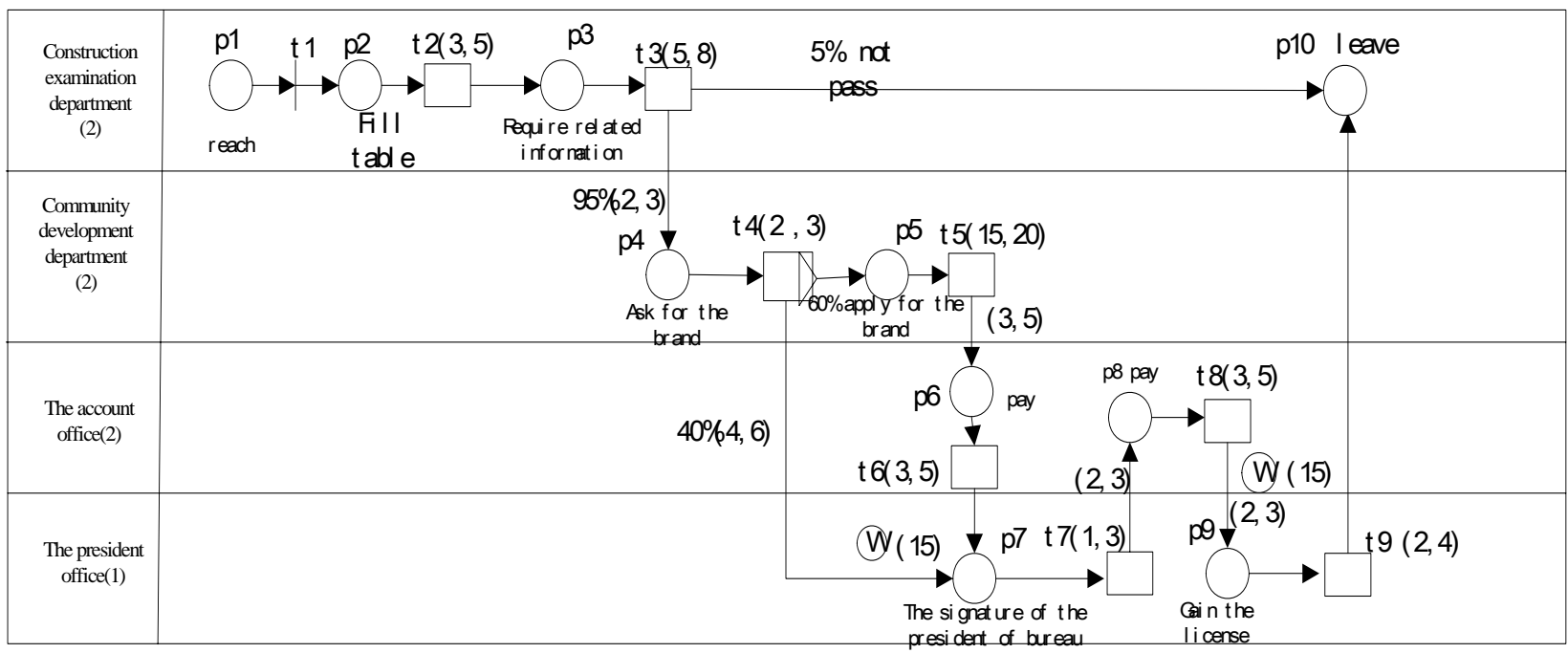

Table 2: The comparison of the performance of the former flow and that of the reorganized one

\begin{tabular}{|c|c|c|c|c|}
\hline $\begin{array}{l}\text { Evaluation } \\
\text { factor }\end{array}$ & category & $\begin{array}{l}\text { Current } \\
\text { situation }\end{array}$ & $\begin{array}{c}\text { After } \\
\text { reorganization }\end{array}$ & contrast \\
\hline \multirow{5}{*}{$\begin{array}{l}\text { Site utilization } \\
\text { ratio ( } \% \text { ) }\end{array}$} & $\begin{array}{l}\text { The president of } \\
\text { bureau office }\end{array}$ & 92 & 52 & $-43.48 \%$ \\
\hline & The account office & 30 & 61 & $103.33 \%$ \\
\hline & $\begin{array}{c}\text { The construction } \\
\text { examination department }\end{array}$ & 31 & 65 & $109.68 \%$ \\
\hline & $\begin{array}{c}\text { Community } \\
\text { development department }\end{array}$ & 80 & 74 & $-7.50 \%$ \\
\hline & $\begin{array}{l}\text { The construction and } \\
\text { personal safety office }\end{array}$ & 45 & & \\
\hline \multirow{2}{*}{$\begin{array}{l}\text { Delay time } \\
\text { ( minute ) }\end{array}$} & $\begin{array}{l}\text { The president of } \\
\text { bureau office }\end{array}$ & 51 & 32 & $-37.25 \%$ \\
\hline & The account office & 6.1 & 4.6 & $-24.59 \%$ \\
\hline
\end{tabular}




\begin{tabular}{|c|c|c|c|c|}
\hline & $\begin{array}{c}\text { The construction } \\
\text { examination department }\end{array}$ & 2.7 & 2.4 & $-11.11 \%$ \\
\hline & $\begin{array}{c}\text { Community } \\
\text { development department }\end{array}$ & 6.5 & 4.2 & $-35.38 \%$ \\
\hline & $\begin{array}{l}\text { he construction and } \\
\text { personal safety office }\end{array}$ & 2.9 & & \\
\hline \multirow{2}{*}{$\begin{array}{l}\text { Period time } \\
\text { ( minute ) }\end{array}$} & Average time & 116.01 & 80.62 & $-30.51 \%$ \\
\hline & Standard division & 2.4 & 1.7 & \\
\hline
\end{tabular}

According to the results of the resembling model, the period for transaction has shortened from 116.01 to 94.716, decreasing 30.51 percent. For different departments, the delay time there has also been reduced to different degrees. For example, the delay period in director of bureau office has reduced from 52 minutes to 32 minutes, a decrease of 37.25 percent; in financial department from 6.1 minutes to 4.6 minutes, a decrease of 24.95 percent; in construction and examination department, a decrease of 11.11 percent and 35.38 percent in the community development office.

Meanwhile, by integrating and reducing relative departments, a new construction and examination department has taken place of the two offices, namely, construction and personal safety office and construction examination office, so departments involved in the flow have changed from 5 to 4 , thus changing the utilizing ratio of these departments.

The utilizing ratio of director of bureau office has reduced 43.48 percent, which leaves more time for the president to handle more affairs in the bureau; the utilizing ratio of account department and construction examination have been increased from 30 percent and 31 percent to 61 percent and 65 percent respectively.

\section{CONCLUSION}

Process simulation is the key technology of process imitation and analysis. Using it to model the business process would standardize the operation of enterprises, and it provides a template for further business process analysis and optimization. This paper proposes a new mode-EEPC-Based Extend Petri net after analyzing and comparing two prevalent modeling technologies: EEPC and Petri net.

Integrating the merits of these two, the extended technology reflects the logic structure of the process, and analyzes the security and expedience of the process qualitatively. At the same time, by adding the factor of time, the performance can be calculated and the process can be analyzed and optimized successfully.
However, this technique has some defaults either: the diagram is too complicated. Although there are various satisfaction-related factors, such as delay time, utilization, cycle time, it is far from enough. In real BPR projects, it needs to consider each business-specific factor, such as cost, fare, output, etc, all of which are yet to be researched closely.

\section{REFERENCES}

1. Ardhadjian, Raffy and Fahner,Mike. "Using Simulation In the Business Process Reengineering Effort", IE/July, 1994. pp. 25-61.

2. Basten,T., Bol, R. and Voorhoeve, M. Simulating and Analyzing Railway Interlockings in ExSpect [C]. IEEE Parallel \& Distributed Technology 1995 Vol.3(3).

3. Castano, S., Antonellis,V. De and Melchiori, M. A Methodology and Tool Environment for Process Analysis and Reengineering. Data and Knowledge Engineering , 1999 , Vol. 31 , No.3 : 253 278.

4. Davenport, T.H. and Short, J.E., "The new industrial engineering: information technology and business process redesign”, Sloan Management Review, Summer 1990, pp. 11-27.

5. Dorador, J.M and Young,R.I.M. Application of IDEF0,IDEF3 and UML methodologies in the creation of information models [J]. Int.Jour. Computer Integrated Manufacturing, 2000,13(5):430-445.

6. Eric, S. K. Yu. Models for Supporting the Redesign of Organizational Work. Conf. On Organizational Computing Systems, 1995.1 7.

7. Fairley, Richard. Software Engineering Concepts McGraw-Hill Book Company 1985, Hwang, Geehyun. Korea Telecom rings the changes using BPR, Strategic Direction, Bradford, Jan 2001,Vol.17, Iss.1, pp20-22.

8. Hammer, M. and Chapy J. Reengineering work: don't automate,obliterate. Harvard Business Review, July- August, 1990, (8):104-112.

9. Hammer, M.and Chapy J. Reengineering the Corporation: A Manifesto for Business 
Revolution, [M]. NewYork, Harper Business , 1993.

10. Kaplan, R.B. and Murdock, L., "Rethinking the corporation: core process redesign”, The McKinsey Quarterly, No. 2, 1991.

11. Kim,Hee-Woong and Kim, Young-Gui. Dynamic process modeling for BPR[C]: A computerized simulation approach. Information \& Management 1997.

12. Kim,Hee-Woong and Kim, Young-Gui. Rationalizing the customer service process, Business Process Management, Bradford,2001, Vol.7, Iss.2,139-154.

13. Kim, C.H and Weston R.H.The complementary use of IDEF and UML modeling approaches [J]. Computers in Industry, 2003, 50:35-56.

14. Kiritsis, D.,Neuendorf, K.P. and Xirouchakis. Petri net techniques for process planning cost estimation. Advances in Engineering Softwar, 1999 , Vol. 30 , No. 6 : pp. 375 387.

15. Kusiak, Andrew, Larson,T.Nick and Wang, Juite. Reengineering of design and manufacturing processes [J], Computers Ind. Engineering, 1994, 26(3): pp. 532-536.

16. Lee, Kyung-Huy and Jung, Moo-Young. Flexible process sequencing using Petri net theory. Computers \& Industrial Engineering, 1995 , Vol. 28 , No.2 : pp. 279 290.

17. Obolensky, Nick. Practical Business Reengingeering Tools \& Techniques for Achieving Effective Change. Kogan Page, 1996. pp. 251 276.

18. Peter, F.Lopes, Fine-tuning Reengineering with Work-flow Automation: Blueprint and Tool. IE, 1993, (8).

19. Petri, Carl A. (1962). "Kommunikation mit Automaten". Ph. D. Thesis. University of Bonn.

20. Ranganathan, A survey of business process reengineering practices in Singapore, Information \& Management, Amsterdam, Dec 2001, Vol. 6, Iss.2, pp. 100-105.

21. Teng, James T.C. , Varun, G. and Fiedler, Business process reengineering: Charting a strategic path for the information age, California Management Review, Berkeley, Spring 1994, Vol. 36, Iss.3, pp. 9-15.

22. Van der Aalst, W.M.P. Workflow Verification: Finding Control-flow Errors Using Petri-net-based Techniques. In W. van der Aalst, J. Desel, and A. Oberweis, editors, Business Process Management. Springer, 2000.

23. Van der Aalst, W.M.P. The Application of Petri Nets to Workflow Management. The Journal of Circuits, Systems and Computers,1998, 8 (1): pp. 21-66.

24. Verbeek, H.M.W, Basten, A.A., and Van der Aalst, W.M.P. Diagnosing Workflow Processes Using Woflan. Computer Journal, 2001, 44(4): p.246.

25. Yen,Hsu-Chun. On the Regularity of Petri Net Languages. Information and Computation , 1996 , Vol. 124 , No.2: pp. 168-181. 